\title{
Mucolipidosis II and III alpha/beta: mutation analysis of 40 Japanese patients showed genotype-phenotype correlation
}

\author{
Takanobu Otomo $^{1}$, Takeshi Muramatsu ${ }^{1}$, Tohru Yorifuji ${ }^{2}$, Torayuki Okuyama ${ }^{3}$, Hiroki Nakabayashi ${ }^{4}$, \\ Toshiyuki Fukao ${ }^{5}$, Toshihiro Ohura ${ }^{6}$, Makoto Yoshino ${ }^{7}$, Akemi Tanaka ${ }^{8}$, Nobuhiko Okamoto ${ }^{9}$, \\ Koji Inui ${ }^{10}$, Keiichi Ozono ${ }^{1}$ and Norio Sakai ${ }^{1}$
}

\begin{abstract}
Mucolipidosis (ML) II alpha/beta and III alpha/beta are autosomal recessive diseases caused by a deficiency of $\alpha$ and/or $\beta$ subunits of the enzyme $N$-acetylglucosamine-1-phosphotransferase, which is encoded by the GNPTAB gene. We analyzed the GNPTAB gene in $25 \mathrm{ML}$ II and $15 \mathrm{ML}$ III Japanese patients. In most ML II patients, the clinical conditions 'stand alone', 'walk without support' and 'speak single words' were impaired; however, the frequency of 'heart murmur', 'inguinal hernia' and 'hepatomegaly and/or splenomegaly' did not differ between ML II and III patients. We detected mutations in GNPTAB in 73 of 80 alleles. Fourteen new mutations were c.914_915insA, c.2089_2090insC, c.2427delC, c.2544delA, c.2693delA, c.3310delG, c.3388_3389insC+c.3392C > T, c.3428_3429insA, c.3741_3744delAGAA, p.R334L, p.F374L, p.H956Y, p.N1153S and duplication of exon 2. Previously reported mutations were p.Q104X, p.W894X, p.R1189X and c.2715+1G $>A$ causing skipping of exon 13. Homozygotes or compound heterozygotes of nonsense and frameshift mutations contributed to the severe phenotype. p.F374L, p.N1153S and splicing mutations contributed to the attenuated phenotype, although coupled with nonsense mutation. These results show the effective molecular diagnosis of ML II and III and also provide phenotypic prediction. This is the first and comprehensive report of molecular analysis for ML patients of Japanese origin. Journal of Human Genetics (2009) 54, 145-151; doi:10.1038/jhg.2009.3; published online 6 February 2009
\end{abstract}

Keywords: genotype-phenotype correlation; GNPTAB; GNPTG; I-cell disease; Japanese; mucolipidosis II alpha/beta; mucolipidosis III alpha/beta; mutation analysis

\section{INTRODUCTION}

Mucolipidosis (ML) is clinically characterized by developmental delay and dysostosis multiplex, which is partially overlapped with mucopolysaccharidoses. ML II and III are autosomal recessive diseases caused by reduced enzyme activity of $\mathrm{N}$-acetylglucosamine-1-phosphotransferase (GlcNAc-phosphotransferase) (EC 2.7.8.17). Targeting of newly synthesized lysosomal enzymes to lysosomes is mediated mainly by mannose-6-phosphate receptor, which recognizes the phosphate at the end of the sugar chain on lysosomal enzymes. The recognition marker is synthesized in a two-step reaction and GlcNAcphosphotransferase acts in the first step. In patients, targeting of many lysosomal enzymes to the lysosome is impaired and levels of overflowed lysosomal enzymes are elevated in the serum and body fluids. ${ }^{1}$

Structural analysis of bovine GlcNAc-phosphotransferase shows that this enzyme is an $\alpha_{2} \beta_{2} \gamma_{2}$ hexameric peptide complex. ${ }^{2}$ In 2000,
Raas-Rothschild et al. ${ }^{3}$ reported that the $\gamma$ subunit is encoded by the GNPTG gene and contributes to the pathology of ML III gamma, formerly described as ML IIIC. ${ }^{4}$ Recent cloning of cDNAs for $\alpha / \beta$ subunits showed that it is encoded by a single gene GNPTAB. ${ }^{5}$ GNPTAB is located at chromosome $12 \mathrm{q} 23.3$, contains 21 exons and codes 1256 amino acids. The $\alpha-\beta$ boundary is located within exon 14 , but the detailed mechanism of processing the precursor into $\alpha$ and $\beta$ subunits is not clear. ${ }^{6}$ A series of genetic-complementation studies have shown heterogeneity in ML III and the genetic relationship between ML II and III. ${ }^{7-9}$ Mutations in GNPTAB cause both the severe type of ML (ML II alpha/beta, ML II, I-cell disease (MIM 252500)) and the attenuated type of ML (ML III alpha/beta, ML IIIA, PseudoHurler polydystrophy (MIM 252600)). ${ }^{10-12}$ Mutations in GNPTG cause the attenuated type of ML (ML III gamma, ML IIIC, ML III variant (MIM 252605)).

\footnotetext{
${ }^{1}$ Department of Pediatrics, Osaka University Graduate School of Medicine, Suita, Osaka, Japan; ${ }^{2}$ Department of Pediatrics, Kyoto University Hospital, Kyoto, Japan; ${ }^{3}$ Department of Clinical Genetics and Molecular Medicine, National Center for Child Health and Development, Tokyo, Japan; ${ }^{4}$ Department of Pediatrics, Surugadai Nihon University Hospital, Tokyo, Japan; ${ }^{5}$ Department of Pediatrics, Graduate School of Medicine, Gifu University, Gifu, Japan; ${ }^{6}$ Department of Pediatrics, Sendai City Hospital, Sendai, Japan; ${ }^{7}$ Department of Pediatrics and Child Health, Kurume University School of Medicine, Kurume, Japan; ${ }^{8}$ Department of Pediatrics, Osaka City University School of Medicine, Osaka, Japan; ${ }^{9}$ Department of Planning and Research, Osaka Medical Center and Research Institute for Maternal and Child Health, Osaka, Japan and ${ }^{10}$ Inui Children's Clinic, Itami, Japan Correspondence: Dr N Sakai, Department of Pediatrics (D-5), Osaka University Graduate School of Medicine, 2-2 Yamada-oka, Suita, Osaka 565-0871, Japan. E-mail: norio@ped.med.osaka-u.ac.jp
}

Received 12 October 2008; revised 1 December 2008; accepted 8 January 2009; published online 6 February 2009 
We analyzed the GNPTAB gene in 40 Japanese ML II and III patients who had been diagnosed clinically or biochemically. Because the previously recorded clinical information was ambiguous, we reviewed the clinical records of these patients. In this article, we show the results of mutation analysis of the GNPTAB gene in 40 Japanese ML II alpha/beta and III alpha/beta patients and the comparison of the obtained genotype and phenotypes.

\section{MATERIALS AND METHODS}

\section{Patients}

The cases were Japanese ML II and III patients diagnosed after the 1970s to date. The diagnosis of ML was based on clinical manifestations and lysosomal enzyme activities in serum, lymphocyte and skin fibroblasts. The number of samples was 40, including 25 samples of ML II and 15 samples of ML III. In this study, all patients were probands and no siblings were included. New patients were informed about the gene test by counselors in each institute and consented. All methods in this study were approved by the ethics committee of Osaka University Graduate School of Medicine.

\section{Clinical information}

The clinical information of each patient followed in our outpatients' clinic was reviewed from the medical records at our institute. To obtain clinical information about patients followed in other institutes, we sent questionnaires to outpatients' doctors or patients' families. Many medical records had been discarded because of the long period since their death or the end of follow-up. In some cases (cases 4, 12, 13, 14 and 34), only information, such as 'ML II patient' or 'I-cell disease', was available.

\section{Cell culture}

Skin fibroblasts of patients were stored in liquid nitrogen at $-196^{\circ} \mathrm{C}$. Half of each thawed sample was subjected to re-culture with Dulbecco's modified Eagle's medium (GIBCO; Grand Island, NY, USA) with 10\% fetal bovine serum and anti-biotic-anti-mycotic (GIBCO). The other half of each frozen sample was directly subjected to RNA and DNA extraction.

\section{Total RNA and genomic DNA extraction}

We extracted total RNA and genomic DNA using a standard extraction kit (Isogen; Nippongene, Tokyo, Japan) from patients' peripheral blood leukocytes and/or cultured skin fibroblasts.

\section{Reverse transcription}

The obtained total RNA was subjected to reverse transcription to construct cDNA. Synthesis of cDNA was performed with M-MLV reverse transcriptase (Invitrogen, Carlsbad, CA, USA) according to the manufacturer's instructions.

\section{Amplification of cDNA and genomic DNA}

A cDNA fragment covering the whole coding region of GNPTAB was amplified by PCR in two fragments (first PCR) and each fragment was secondarily amplified in two fragments (second PCR). In other words, whole cDNA was amplified in four overlapping fragments. Six pairs of primer sequences for amplification of cDNA are listed in Supplementary 1. For genomic DNA amplification of each exon of GNPTAB by PCR, we used genomic primers described earlier by Kudo et al. ${ }^{10}$ (primer ID; 1088, 1076, 1077, 1078, 1082, $1118,1119,1085,1086,1089,1107,1092,1109,1120,1121,1122,1123,1163$, $1164,1129,1134,1135,1136,1215,1216,1139,1140,1141,1142,1219$ and 1259 ) and other newly designed primers (Supplementary 1). For the amplification of each exon of GNPTG, we used primers described earlier by RaasRothschild $e t \mathrm{al}^{3}$ and other newly designed primers (Supplementary 1). PCR reactions were conducted in $20 \mu$ reaction volumes with rTaq DNA polymerase (Takara Bio Inc., Otsu, Japan). The basic thermal profile consisted of initial denaturation at $94{ }^{\circ} \mathrm{C}$ for $2 \mathrm{~min}$, followed by 35 cycles at $94{ }^{\circ} \mathrm{C}$ for $1 \mathrm{~min}, 56^{\circ} \mathrm{C}$ for $2 \mathrm{~min}$ and $72^{\circ} \mathrm{C}$ for $2 \mathrm{~min}$, with a final extension at $72{ }^{\circ} \mathrm{C}$ for $7 \mathrm{~min}$. Annealing temperature was modified within 55 and $60^{\circ} \mathrm{C}$. Three microliters of each PCR mixture were run on agarose gel to ensure that only the specific product was amplified.

\section{DNA sequencing}

PCR products were purified using a standard kit (SUPREC-02; Takara Bio Inc.) to remove unnecessary primers and finally dissolved in pure water at a concentration of approximately $2-10 \mathrm{ng}^{-1}$ water as a sequencing reaction template. DNA sequencing was carried out with the same primers as mentioned above (Supplementary 1) using the BigDye Terminator V1.1 cycle sequencing kit (Applied Biosystems, Foster City, CA, USA) and the Applied Biosystems 3100 genetic analyzer according to the manufacturer's instructions. First, DNA sequencing was performed for CDNAs of GNPTAB followed by the confirmation by genomic DNA sequencing. We also analyzed the genomic DNA sequence of GNPTG in seven patients in whom only one mutation in GNPTAB was detected.

\section{Screening for p.F374L and p.R1189X mutation by restriction} fragment length polymorphism

DNA fragments containing the mutation site were amplified by PCR with primer 343/1109 (Supplementary 1) (Kudo et al..$^{10}$ ) and 230/232 (Supplementary 1) and digested by restriction enzyme Mbo II or Taq I, respectively. PCR fragments containing p.F374L were recognized by $M b o$ II and digested from 367 to $33+16+97+221 \mathrm{bp}$. The same fragments derived from the normal allele were digested from 367 to $33+16+318 \mathrm{bp}$. With regard to PCR fragments containing p.R1189X, Taq I recognizes only the normal sequence and digests the fragment of $293 \mathrm{bp}$ length into $205+88 \mathrm{bp}$ fragments. If mutations were found by this method, DNA sequences were confirmed by genomic DNA sequencing by the same method as described above.

\section{RESULTS}

Mutations in ML II alpha/beta and III alpha/beta patients

We detected 73 mutant alleles of 80 alleles in 40 Japanese patients (Table 1). Bold letters indicate new mutations detected in this study. These include 14 new mutations and four previously detected mutations. All four known mutations were reported by a Korean group ${ }^{11}$ and one, p.R1189X, was also reported by an Israeli group in a patient of Irish/Scottish origin. ${ }^{13}$ The most frequent mutation was the nonsense mutation p.R1189X (c.3565C > T) and its allele frequency was $33 / 80(=41.25 \%)$ in the analyzed alleles of all ML II and III patients. In 90 healthy individuals, this mutation was not found by the restriction fragment length polymorphism method described above. p.F374L was found in 1 of 25 ML II patients and 7 of 15 ML III patients, and total allele frequency was $8 / 80(=10.00 \%)$. Duplication of exon 2 was found in 1 of 25 ML II patients and 5 of 15 ML III patients, and total allele frequency was $6 / 80(=7.50 \%)$. No mutation was found in GNPTG in seven patients in whom only one mutation was detected in GNPTAB.

\section{Analysis of the duplication of exon 2}

First, we found mutant alleles with the structure of duplicating exon 2 in cDNA analysis (Figure 1c). We constructed forward and reverse primers within exon 2 (primer 336/335) and performed long PCR with an XL PCR Kit (Applied Biosystems). The basic thermal profile consisted of initial denaturation at $94^{\circ} \mathrm{C}$ for $1 \mathrm{~min}$, followed by 35 cycles at $94{ }^{\circ} \mathrm{C}$ for $15 \mathrm{~s}, 62^{\circ} \mathrm{C}$ for $12 \mathrm{~min}$, with a final extension at $72^{\circ} \mathrm{C}$ for $15 \mathrm{~min}$. None was amplified with normal alleles by this method because each primer runs the other way. With a mutant allele, a specific fragment was amplified and the size of the fragment was estimated as approximately $15 \mathrm{kbp}$ by agarose gel electrophoresis (Figure 1d). Sequencing analysis of this fragment was performed by primer walking and the junction between introns 1 and 2 was confirmed (Figure 1b); however, we could not detect any rearrangement between exons 1 and 2 by primer walking (data not shown). 
Table 1 Summary of all mutations in GNPTAB identified in this study

\begin{tabular}{|c|c|c|}
\hline Case & Position & $D N A$ \\
\hline \multicolumn{3}{|c|}{ ML // alpha/beta } \\
\hline \multirow[t]{2}{*}{1} & Exon 19 & c. $3565 \mathrm{C}>\mathrm{T}$ \\
\hline & Exon 19 & c. $3565 \mathrm{C}>\mathrm{T}$ \\
\hline \multirow[t]{2}{*}{2} & Exon 13 & c.2089_2090insC \\
\hline & Exon 19 & c. $3565 C>T$ \\
\hline \multirow[t]{2}{*}{3} & Exon 8 & c.914_915insA \\
\hline & Exon 19 & c. $3565 \mathrm{C}>\mathrm{T}$ \\
\hline \multirow[t]{2}{*}{4} & Exon 19 & c. $3565 \mathrm{C}>\mathrm{T}$ \\
\hline & ND & ND \\
\hline \multirow[t]{2}{*}{5} & Exon 13 & c. $2681 \mathrm{G}>\mathrm{A}$ \\
\hline & Exon 19 & c. $3565 \mathrm{C}>\mathrm{T}$ \\
\hline \multirow[t]{2}{*}{6} & Exon 10 & c. $1120 \mathrm{~T}>\mathrm{C}$ \\
\hline & ND & ND \\
\hline \multirow[t]{2}{*}{7} & Exon 19 & c. $3565 \mathrm{C}>\mathrm{T}$ \\
\hline & Exon 19 & c. $3565 \mathrm{C}>\mathrm{T}$ \\
\hline \multirow[t]{2}{*}{8} & Exon 19 & c. $3565 \mathrm{C}>\mathrm{T}$ \\
\hline & Exon 19 & c. $3565 C>T$ \\
\hline \multirow[t]{2}{*}{9} & Exon 19 & c. $3565 \mathrm{C}>\mathrm{T}$ \\
\hline & Exon 19 & c. $3565 C>T$ \\
\hline \multirow[t]{2}{*}{10} & Exon 19 & c. $3565 \mathrm{C}>\mathrm{T}$ \\
\hline & Exon 19 & c. $3565 \mathrm{C}>\mathrm{T}$ \\
\hline \multirow[t]{2}{*}{11} & Exon 13 & c.2427delC \\
\hline & Exon 19 & c. $3565 \mathrm{C}>\mathrm{T}$ \\
\hline \multirow[t]{2}{*}{12} & Exon 18 & c.3388_3389insC+c.3392C $>T$ \\
\hline & ND & ND \\
\hline \multirow[t]{2}{*}{13} & Exon 9 & c. $1001 \mathrm{G}>\mathrm{T}$ \\
\hline & Exon 19 & c. $3565 \mathrm{C}>\mathrm{T}$ \\
\hline \multirow[t]{2}{*}{14} & Exon 2 & Duplication exon 2 \\
\hline & Exon 13 & c.2544delA \\
\hline \multirow[t]{2}{*}{15} & Exon 3 & c. $310 \mathrm{C}>\mathrm{T}$ \\
\hline & Exon 19 & c. $3565 \mathrm{C}>\mathrm{T}$ \\
\hline \multirow[t]{2}{*}{16} & Exon 3 & c. $310 \mathrm{C}>\mathrm{T}$ \\
\hline & Exon 3 & c. $310 \mathrm{C}>\mathrm{T}$ \\
\hline \multirow[t]{2}{*}{17} & Exon 19 & c. $3565 \mathrm{C}>\mathrm{T}$ \\
\hline & Exon 19 & c. $3565 \mathrm{C}>\mathrm{T}$ \\
\hline \multirow[t]{2}{*}{18} & Exon 17 & c.3310delG \\
\hline & Exon 18 & c.3428_3429insA \\
\hline \multirow[t]{2}{*}{19} & Exon 19 & c. $3565 \mathrm{C}>\mathrm{T}$ \\
\hline & ND & ND \\
\hline \multirow[t]{2}{*}{20} & Exon 21 & c.3741_3744delAGAA \\
\hline & ND & ND \\
\hline \multirow[t]{2}{*}{21} & Exon 13 & c.2544delA \\
\hline & Exon 13 & c.2544delA \\
\hline 22 & Exon 3 & c. $310 \mathrm{C}>\mathrm{T}$ \\
\hline & Exon 19 & c. $3565 \mathrm{C}>\mathrm{T}$ \\
\hline 23 & Exon 19 & c. $3565 \mathrm{C}>\mathrm{T}$ \\
\hline & Exon 19 & c. $3565 \mathrm{C}>\mathrm{T}$ \\
\hline 24 & Exon 19 & c. $3565 \mathrm{C}>\mathrm{T}$ \\
\hline & ND & ND \\
\hline 25 & Exon 19 & c. $3565 \mathrm{C}>\mathrm{T}$ \\
\hline & Exon 19 & c. $3565 \mathrm{C}>\mathrm{T}$ \\
\hline
\end{tabular}

ML III alpha/beta

$\begin{array}{lll}26 & \text { Intron 13 } & \text { c.2715+1G }>\text { A } \\ & \text { Exon 19 } & \text { c.3565C }>\mathrm{T} \\ 27 & \text { Exon 10 } & \text { c.1120T }>\text { C } \\ & \text { Exon 19 } & \text { c.3565C }>\mathrm{T} \\ 28 & \text { Exon 2 } & \text { Duplication exon 2 } \\ & \text { Exon 13 } & \text { c.2089_2090insC }\end{array}$

Protein

p.R1189X

p.R1189X

p.L697fs

p.R1189X

p.D305fs

p.R1189X

p.R1189X

ND

p.W894X

p.R1189X

p.F374L

ND

p.R1189X

p.R1189X

p.R1189X

p.R1189X

p.R1189X

p.R1189X

p.R1189X

p.R1189X

p.L810fs

p.R1189X

p.V1130fs

ND

p.R334L

p.R1189X

Frameshift

p.K848fs

p.Q104X

p.R1189X

p.Q104X

p.Q104X

p.R1189X

p.R1189X

p.A1104fs

p.N1143fs

p.R1189X

ND

p.E1248fs

ND

p.K848fs

p.K848fs

p.Q104X

p.R1189X

p.R1189X

p.R1189X

p.R1189X

ND

p.R1189X

p.R1189X

(skip Exon 13)

p.R1189X

p.F374L

p.R1189X

Frameshift

p.L697fs
Table 1 Continued

\begin{tabular}{|c|c|c|c|}
\hline Case & Position & $D N A$ & Protein \\
\hline \multirow[t]{2}{*}{29} & Exon 2 & Duplication exon 2 & Frameshift \\
\hline & Exon 13 & c.2693delA & p.K898fs \\
\hline \multirow[t]{2}{*}{30} & Exon 2 & Duplication exon 2 & Frameshift \\
\hline & ND & ND & ND \\
\hline \multirow[t]{2}{*}{31} & Exon 2 & Duplication exon 2 & Frameshift \\
\hline & Exon 13 & c.2544delA & p.K848fs \\
\hline \multirow[t]{2}{*}{32} & Exon 2 & Duplication exon 2 & Frameshift \\
\hline & Exon 10 & c. $1120 \mathrm{~T}>\mathrm{C}$ & p.F374L \\
\hline \multirow[t]{2}{*}{33} & Exon 19 & c. $3458 \mathrm{~A}>\mathrm{G}$ & p.N1153S \\
\hline & Exon 19 & c. $3565 C>T$ & p.R1189X \\
\hline \multirow[t]{2}{*}{34} & Intron 13 & c. $2715+1 G>A$ & (skip Exon 13) \\
\hline & Exon 14 & c. $2866 \mathrm{C}>\mathrm{T}$ & p.H956Y \\
\hline \multirow[t]{2}{*}{35} & Exon 10 & c. $1120 \mathrm{~T}>\mathrm{C}$ & p.F374L \\
\hline & Exon 13 & c. $2681 \mathrm{G}>\mathrm{A}$ & p.W894X \\
\hline \multirow[t]{2}{*}{36} & Intron 1 & c. $2715+1 \mathrm{G}>\mathrm{A}$ & (skip Exon 13) \\
\hline & Exon 14 & c. $2866 \mathrm{C}>\mathrm{T}$ & p.H956Y \\
\hline \multirow[t]{2}{*}{37} & Exon 10 & c. $1120 \mathrm{~T}>\mathrm{C}$ & p.F374L \\
\hline & Exon 19 & c. $3565 \mathrm{C}>\mathrm{T}$ & p.R1189X \\
\hline \multirow[t]{2}{*}{38} & Exon 10 & c. $1120 \mathrm{~T}>\mathrm{C}$ & p.F374L \\
\hline & Exon 19 & c. $3565 \mathrm{C}>\mathrm{T}$ & p.R1189X \\
\hline \multirow[t]{2}{*}{39} & Exon 10 & c. $1120 \mathrm{~T}>\mathrm{C}$ & p.F374L \\
\hline & Exon 19 & c. $3565 C>T$ & p.R1189X \\
\hline \multirow[t]{2}{*}{40} & Exon 10 & c. $1120 \mathrm{~T}>\mathrm{C}$ & p.F374L \\
\hline & Exon 19 & c. $3565 C>T$ & p.R1189X \\
\hline
\end{tabular}

Abbreviations: ML, mucolipidosis; ND, not detectable.

Bold letters indicate novel mutations detected in this study. Numbering of nucleotides starts with +1 at the first nucleotide of the initiation codon and numbering of amino acid starts with the first methionine encoded by the ATG. Descriptions about CDNA mutation and mutant protein mainly conform to the 'Nomenclature for the description of sequence variations' by Human

Genome Variation Society (http://www.hgvs.org/mutnomen/).

\section{Polymorphisms in GNPTAB}

The 14 polymorphisms in GNPTAB found in this study are listed in Table 2. Ten polymorphisms were found within the intron and four within the coding region that does not change the amino-acid residue. Not all patients were tested because these polymorphisms were found incidentally in the process of sequencing analysis of mutations. Twelve polymorphisms have been registered in dbSNP (http:// www.ncbi.nlm.nih.gov/SNP/). Two polymorphisms have not been reported previously.

\section{Clinical phenotypes and genotypes}

A summary of the clinical images and types of mutations of patients is shown in Table 3. We chose simple clinical manifestations, such as standing or walking, speaking, heart murmur, inguinal hernia and hepatosplenomegaly, which could be easily retrieved from old medical records or the memory of the doctors who followed them. Only the ML type was recorded in some cases but we could not obtain further information. The frequency of each clinical manifestation in the two groups is shown in Table 4.

In 33 patients, mutation was detected in both alleles. We arranged all cases into eight groups based on the type of mutation, respectively (Table 3).

Nonsense mutation contains p.Q104X, p.W894X and p.R1189X. Frameshift contains a type of mutation caused by the insertion or deletion of 1 or 4 bases, including c.914_915insA, c.2089_2090insC, c.2427delC, c.2544delA, c.2693delA, c.3310delG, c.3388_3389insC + c.3392C > T, c.3428_3429insA and c.3741_3744delAGAA. Each missense mutation, p.R334L, p.F374L, p.H956Y and p.N1153S, is 

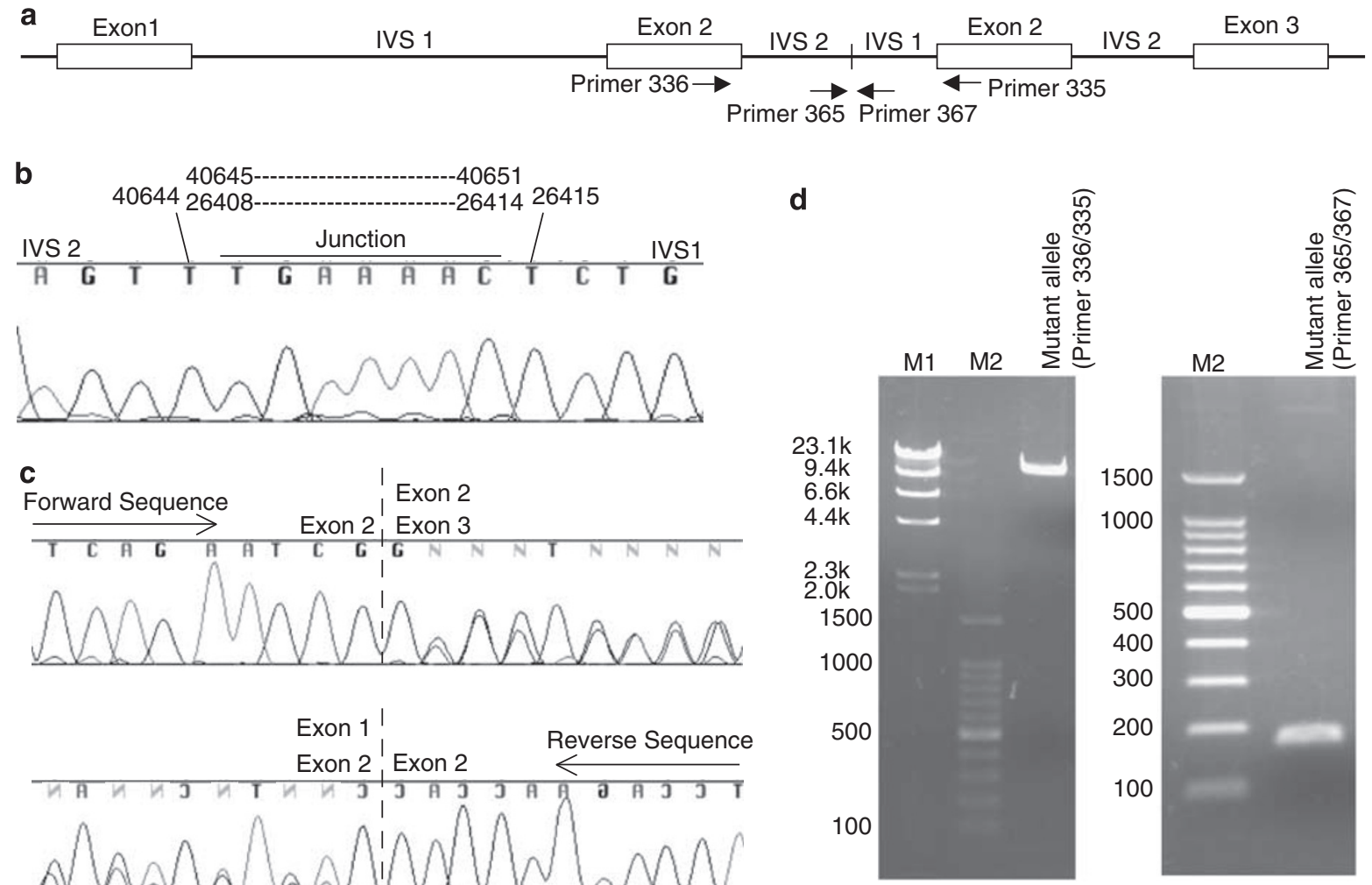

Figure 1 Summary of the duplication exon 2. (a) Overview of rearranged mutant allele. (b) Genomic sequence around the junction. XL PCR product of primer set 336/335 was used as a sequence template. Sequencing analysis of mutant allele showed that IVS 2 jumped and connected to IVS 1 through 7 overlapping bases. The number above indicates the position in reference sequence NT_019546.15. (c) Sequence analysis of cDNA. Forward sequencing showed overlapped signal of exons 2 and 3 next to the end of exon 2. Reverse sequencing also showed overlapped signal of exons 1 and 2 next to the end of exon 2. (d) Agarose gel electrophoresis of PCR products amplified by primer set $336 / 335$ and $365 / 367$. These primers were designed to run the other way, respectively, and only the mutant allele was amplified. Left figure indicates that the amplified fragment by primer set 336/335 was estimated to be about $15 \mathrm{kbp}$. We then sequenced the fragment by primer walking. The junction was found and primers were designed near the junction. Right figure indicates the PCR fragment amplified by primer set $365 / 367$. Estimated fragment size was $177 \mathrm{bp}$. M1 is a ladder of $\lambda /$ Hind III marker and M2 is a ladder of $100 \mathrm{bp}$ marker (Takara Bio Inc.).

\section{Table 2 Polymorphisms in GNPTAB}

\begin{tabular}{|c|c|c|c|}
\hline Position ${ }^{a}$ & $\begin{array}{l}\text { Location } \\
\text { in GNPTAB }\end{array}$ & $\begin{array}{c}\text { Genomic DNA } \\
\text { polymorphism }^{\mathrm{b}}\end{array}$ & $C D N A^{\mathrm{C}}$ \\
\hline 25706627 & Exon 1 & $G>A$ & c. $18 \mathrm{G}>\mathrm{A}$ (synonymous) \\
\hline 25666041 & Intron 2 & $\mathrm{G}>\mathrm{T}$ & \\
\hline 25665434_36 & Intron 3 & ATA $>$ A (del2bases) $)^{d}$ & \\
\hline 25665015 & Intron 3 & $A>G$ & \\
\hline 25664898 & Intron 3 & $\mathrm{~T}>\mathrm{A}$ & \\
\hline 25664420_24 & Intron 4 & TGTGT > TGT (del2bases) & \\
\hline 25664372 & Intron 4 & $\mathrm{C}>\mathrm{T}$ & \\
\hline 25662419 & Intron 4 & $G>A$ & \\
\hline 25641086 & Exon 13 & $C>G^{d}$ & c. $1800 C>$ G (synonymous) \\
\hline 25640954 & Exon 13 & $A>G$ & c. $1932 \mathrm{~A}>\mathrm{G}$ (synonymous) \\
\hline 25640405 & Exon 13 & $\mathrm{C}>\mathrm{T}$ & c. $2481 \mathrm{C}>\mathrm{T}$ (synonymous) \\
\hline 25637091 & Intron 15 & $\mathrm{~T}>\mathrm{C}$ & \\
\hline 25633304 & Intron 17 & $\mathrm{~T}>\mathrm{C}$ & \\
\hline 25633069 & Intron 18 & $C>G$ & \\
\hline
\end{tabular}

aPosition in the reference sequence NT 019546.15.

bNucleotide changes from the reference sequence NT_019546.15.

cNumbering of nucleotides starts with +1 at the first nucleotide of the initiation codon. ${ }^{d}$ New polymorphisms detected in this study. enumerated individually. Duplication of exon 2 and skipping of exon 13 are also enumerated individually, although they finally cause frameshift. Homozygotes or compound heterozygotes of the mutation are indicated by a closed circle and heterozygotes by an open circle.

\section{DISCUSSION}

In this study, several frequent mutations were detected. Nonsense mutation c.3565C $>$ T (p.R1189X) was especially frequent in our study and its allele frequency was $41.25 \%$. Eight of $25 \mathrm{ML}$ II patients have this mutation homozygously. According to previous reports, this mutation was only found in two Korean cases ${ }^{11}$ and in one case of Irish/Scottish origin. ${ }^{13}$ This mutation seems to be common in eastern Asia, including Japan. It is speculated that it does not occur in a hot spot but by a founder effect, although experimental confirmation is difficult because of the unavailability of samples from the patients' parents. The secondary frequent mutation is a missense mutation c.1120C > T (p.F374L) found in eight alleles compounded heterozygously with another mutation in this study. Duplication of exon 2 was found in six alleles and this mutation occurred at the genomic level of rearrangement. Sequencing analysis of the fragment from the tail of exon 2 to the head of exon 2 showed the junction between introns 1 


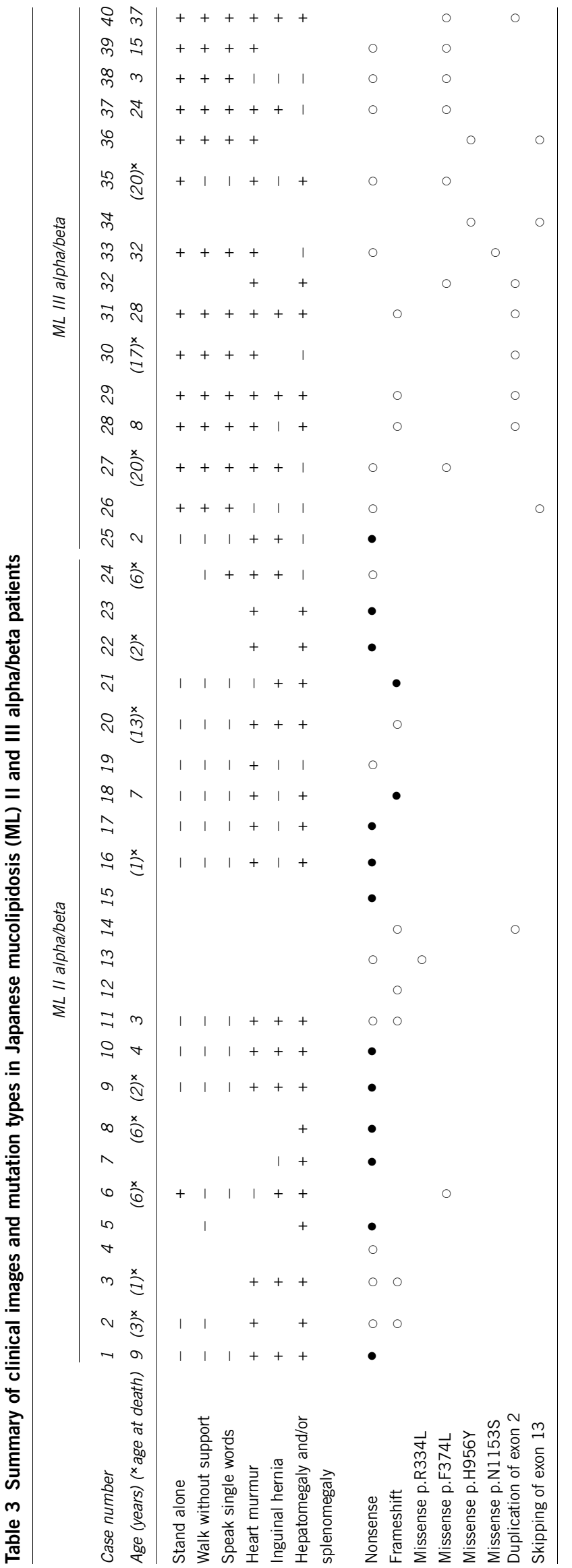

Table 4 Clinical manifestations and mucolipidosis (ML) types

\begin{tabular}{lcc}
\hline Clinical manifestations & ML II & ML III \\
\hline Stand alone & $1 / 13$ & $13 / 13$ \\
Walk without support & $0 / 15$ & $12 / 13$ \\
Speak single words & $1 / 13$ & $12 / 13$ \\
Heart murmur & $15 / 17$ & $12 / 14$ \\
Inguinal hernia & $10 / 15$ & $5 / 9$ \\
Hepatomegaly and/or splenomegaly & $17 / 20$ & $6 / 12$
\end{tabular}

and 2; however, there was no junction between exons 1 and 2 by primer walking. We suggest that this rearrangement is not derived from insertion of a region containing exon 2 but from the recombination between introns 1 and 2 (Figure 1a). Skipping of exon 13 is also frequent and is caused by the intronic one-base substitution c. $2715+1 \mathrm{G}>\mathrm{A}$ mutation. This mutation is discussed in detail in the previous article. $^{11}$

We examined the founder effects of several mutations based on the result of polymorphisms. We show the genotype frequencies of several polymorphisms in patients with/without p.F374L and c.2715+1G > A (Table 5). Reference frequencies are data from HapMap-JPT (Japanese in Tokyo, Japan) in the International HapMap project. Our results indicate that six single-nucleotide polymorphism (SNPs) (rs10778150, rs2108694, rs6539012, rs10778148, rs759935 and rs376475) are coincident with mutation p.F374L and the SNP (rs3751249) with c. $2715+1 \mathrm{G}>\mathrm{A}$ in Japanese ML patients. We suggest that high correspondence between the two mutations and SNPs is most likely explained by a founder effect. With regard to the other mutations, there seemed to be no relationship between the mutations and polymorphisms.

Traditionally, ML patients have been classified into severe type (as type II) and attenuated type (as type III). We examined genotypephenotype correlation with the obtained mutational information and patient diagnosis, namely ML type. Patients with a combination of homozygotes or compound heterozygotes within nonsense mutation, p.Q104X, p.W894X and p.R1189X, showed clinically severe phenotypes. Frameshift mutations caused by insertion or deletion of 1 or 4 bases (c.914_915insA, c.2089_2090insC, c.2427delC, c.2544delA, c.2693delA, c.3310delG, c.3388_3389insC+c.3392C > T, c.3428_3429 insA, c.3741_3744delAGAA) also contribute to the severe phenotype.

On the other hand, p.F374L is considered to contribute to relatively mild clinical manifestations, except for case 6, which was reported in detail by Kojima et al. ${ }^{14}$ and also by Okada et al. ${ }^{15}$ (case 9 in the article). He could stand alone but could not walk and was classified into ML II. We think that this was not a typical ML II case and showed a relatively attenuated phenotype. The other cases of p.F374L, if combined with nonsense or frameshift mutation, clinically showed ML III.

Duplication of exon 2 was found in attenuated cases, except for case 14; however, we cannot discuss case 14 further because limited information was available. We consider that duplication of exon 2 contributes to the attenuated phenotype. c.2715+1G $>$ A causes skipping of exon $13 .{ }^{11}$ Case 26 has p.R1189X and c.2715+1G $>$ A and shows an attenuated clinical phenotype. We consider that c. $2715+1 \mathrm{G}>\mathrm{A}$ also contributes to the attenuated phenotype.

Exon 2 contains 86 base sequences and exon 13 contains 1103 base sequences. The above two mutations consequently lead to frameshift. The Korean group reported skipping of exon 13 only in ML III 
Table 5 Genotype frequencies of mutations and polymorphisms

\begin{tabular}{|c|c|c|c|c|c|c|c|c|}
\hline \multirow[t]{2}{*}{ Position $^{\mathrm{a}}(d b S N P$ id) } & \multirow{2}{*}{$\begin{array}{l}\text { Population } \\
\text { HapMap-JPT }\end{array}$} & \multicolumn{6}{|c|}{ Genotype frequency } & \multirow[t]{2}{*}{$\mathrm{n}$} \\
\hline & & $\mathrm{T} / \mathrm{T}$ & 0 & $\mathrm{~T} / \mathrm{A}$ & 0.111 & $A / A$ & 0.889 & \\
\hline \multirow[t]{2}{*}{25664898 (rs10778150) } & Without p.F374L & & 0 & & 0 & & 1.000 & 8 \\
\hline & HapMap-JPT & $\mathrm{C} / \mathrm{C}$ & 0 & $\mathrm{C} / \mathrm{T}$ & 0.119 & $\mathrm{~T} / \mathrm{T}$ & 0.881 & \\
\hline \multirow[t]{2}{*}{25664372 (rs2108694) } & Without p.F374L & & 0 & & 0 & & 1.000 & 6 \\
\hline & HapMap-JPT & $\mathrm{G} / \mathrm{G}$ & 0.023 & $\mathrm{G} / \mathrm{A}$ & 0.114 & $\mathrm{~A} / \mathrm{A}$ & 0.864 & \\
\hline \multirow[t]{3}{*}{25662419 (rs6539012) } & Without p.F374L & & 0 & & 0.143 & & 0.857 & 14 \\
\hline & p.F374L hetero & & 0 & & 1.000 & & 0 & 6 \\
\hline & HapMap-JPT & $\mathrm{A} / \mathrm{A}$ & 0 & $\mathrm{~A} / \mathrm{G}$ & 0.244 & $\mathrm{G} / \mathrm{G}$ & 0.756 & \\
\hline 25640954 (rs10778148) & Without p.F374L & & 0 & & 0.133 & & 0.867 & 15 \\
\hline \multirow{2}{*}{25637091 (rs759935) } & p.F374L hetero & & 0 & & 1.000 & & 0 & 5 \\
\hline & HapMap-JPT & $\mathrm{C} / \mathrm{C}$ & 0 & $\mathrm{C} / \mathrm{G}$ & 0.250 & $G / G$ & 0.750 & \\
\hline \multirow[t]{3}{*}{25633069 (rs3736475) } & Without p.F374L & & 0 & & 0.143 & & 0.857 & 14 \\
\hline & p.F374L hetero & & 0 & & 1.000 & & 0 & 4 \\
\hline & HapMap-JPT & $\mathrm{C} / \mathrm{C}$ & 0.977 & $\mathrm{C} / \mathrm{T}$ & 0.023 & $\mathrm{~T} / \mathrm{T}$ & 0 & \\
\hline \multirow[t]{2}{*}{25640405 (rs3751249) } & Without c. $2715+1 \mathrm{G}>\mathrm{A}$ & & 1.000 & & 0 & & 0 & 18 \\
\hline & c. $2715+1 G>A$ hetero & & 0 & & 1.000 & & 0 & 3 \\
\hline
\end{tabular}

' $n$ ' means the number of patients tested for single-nucleotide polymorphisms.

Bold letters indicate major genotypes within each row.

aposition in the reference sequence NT_019546.15.

patients. Kudo et al. reported a case in which splicing mutation caused an attenuated phenotype with highly suppressed enzyme activity and suggested that splicing was especially disrupted only in these fibroblasts. Our results are consistent, although the detailed mechanisms remain unclear.

Case 33 has compound heterozygosity of p.R1189X and p.N1153S. This case shows one of the most attenuated phenotypes in this study; she could speak and walk when she was 1 year old, without hepatosplenomegaly, and she is now 32 years old and working in a workshop. p.N1153S was found in only one allele; however, it is suggested that this mutation contributes to the attenuated phenotype.

In this study, clinical severity proved to be well correlated with mutational severity. Our result supports the previous report by Bargal et al. ${ }^{13}$ On the basis of information about known mutations, a patient's clinical phenotype can be estimated. Even if new mutations are found, some clinical phenotypes can be predicted by the type of mutation.

We investigated the correlation between clinical manifestations and diagnosed ML types (Table 4). 'Stand alone', 'walk without support' and 'speak single words' are considered to well correlate to the ML type. In other words, a patient who cannot stand, walk or speak has a severe phenotype and life expectancy is estimated to be limited, generally called 'ML II'. Clinical manifestations, such as 'heart murmur', 'inguinal hernia' and 'hepatomegaly and/or splenomegaly', were found in both ML II and III. Unfortunately, other various clinical manifestations, such as 'age at onset', 'bone deformity' and 'neurological findings', could not be examined because of poor information about many cases in this study. If a large-scale prospective investigation about the natural history of ML is carried out in the future, these problems may be solved.

Mucolipidosis II alpha/beta and III alpha/beta are caused by the same gene, GNPTAB, and the clinical phenotype shows a continuum from mild to severe. In both ML II and III, life expectancy is becoming longer owing to improved supportive therapy and care. Previously classified ML II patients can now live for more than 10 years; however, there are undoubtedly differences between typical ML II and III. It is difficult to predict the clinical phenotype from only enzymatic or biochemical characteristics. ${ }^{15}$ From a clinical standpoint, early prediction of prognosis is necessary. We could clearly classify the former ML types from selected clinical manifestations and these ML types correlated with genotypes. This is useful for predicting prognosis to analyze mutations for treatment, including hematopoietic stem cell transplantation, especially in attenuated cases diagnosed in the early stage by molecular analysis. ${ }^{16}$

According to the recent report, ${ }^{17} 23$ different mutations have been reported in the GNPTAB gene causing ML II and III alpha/beta. We detected 14 new mutations in the Japanese population. Three of four other already known mutations detected this time were reported only in Korean patient. This indicates that mutations found in Asian people are restricted to the Asian region and seem not to be derived from hot spots.

This is the first and comprehensive report of molecular analysis for Japanese patients of ML. Our data showed genotype-phenotype correlations in Japanese ML II and III (alpha/beta) in particular 
mutations. This result provides effective molecular diagnosis and phenotypic prediction of ML II and III (alpha/beta). Additionally, we showed that clinical severity and life expectancy are also predicted by particular clinical manifestations, including standing alone, walking without support and speaking single words.

\section{ACKNOWLEDGEMENTS}

This study was supported in part by grants from the Research on Measures for Intractable Diseases, the Ministry of Health, Labour and Welfare in Japan.

1 Kornfeld, S. \& Sly, W. S. I-cell disease and Pseudo-Hurler Polydystrophy: Disorders of lysosomal enzyme phosphorylation and localization. In The Metabolic and Molecular Bases of Inherited Disease (eds Scriver, C. R., Beaudet, A. L., Sly, W. S., Valle, D.) Ch. 138, 3469-3482 (McGraw-Hill, New York, 2001).

2 Bao, M., Booth, J. L., Elmendorf, B. J. \& Canfield, W. M. Bovine UDP-N-acetylglucosamine:lysosomal-enzyme $\mathrm{N}$-acetylglucosamine-1-phosphotransferase. I. Purification and subunit structure. J. Biol. Chem. 271, 31437-31445 (1996).

3 Raas-Rothschild, A., Cormier-Daire, V., Bao, M., Genin, E., Salomon, R., Brewer, K. et al. Molecular basis of variant pseudo-hurler polydystrophy (mucolipidosis IIIC). J. Clin. Invest. 105, 673-681 (2000).

4 Cathey, S. S., Kudo, M., Tiede, S., Raas-Rothschild, A., Braulke, T., Beck, M. et al. Molecular order in mucolipidosis II and III nomenclature. Am. J. Med. Genet. A 146A, 512-513 (2008).

5 Kudo, M., Bao, M., D'Souza, A., Ying, F., Pan, H., Roe, B. A. et al. The alpha- and betasubunits of the human UDP- $N$-acetylglucosamine:lysosomal enzyme $\mathrm{N}$-acetylglucosamine-1-phosphotransferase [corrected] are encoded by a single cDNA. J. Biol. Chem. 280, 36141-36149 (2005).

6 Kudo, M. \& Canfield, W. M. Structural requirements for efficient processing and activation of recombinant human UDP- $N$-acetylglucosamine: lysosomal-enzyme- $N$-acetylglucosamine-1-phosphotransferase. J. Biol. Chem. 281, 11761-11768 (2006)
7 Honey, N. K., Mueller, O. T., Little, L. E., Miller, A. L. \& Shows, T. B. Mucolipidosis III is genetically heterogeneous. Proc. Natl. Acad. Sci. USA 79, 7420-7424 (1982).

8 Mueller, O. T., Honey, N. K., Little, L. E., Miller, A. L. \& Shows, T. B. Mucolipidosis II and III. The genetic relationships between two disorders of lysosomal enzyme biosynthesis. J. Clin. Invest. 72, 1016-1023 (1983).

9 Little, L. E., Mueller, O. T., Honey, N. K., Shows, T. B. \& Miller, A. L. Heterogeneity of $\mathrm{N}$-acetylglucosamine-1-phosphotransferase within mucolipidosis III. J. Biol. Chem. 261, 733-738 (1986).

10 Kudo, M., Brem, M. S. \& Canfield, W. M. Mucolipidosis II (I-cell disease) and mucolipidosis IIIA (classical pseudo-hurler polydystrophy) are caused by mutations in the GlcNAc-phosphotransferase alpha/beta-subunits precursor gene. Am. J. Hum. Genet. 78, 451-463 (2006).

11 Paik, K. H., Song, S. M., Ki, C. S., Yu, H. W., Kim, J. S., Min, K. H. et al. Identification of mutations in the GNPTA (MGC4170) gene coding for GlcNAc-phosphotransferase alpha/beta subunits in Korean patients with mucolipidosis type II or type IIIA. Hum. Mutat. 26, 308-314 (2005).

12 Tiede, S., Storch, S., Lübke, T., Henrissat, B., Bargal, R., Raas-Rothschild, A. et al. Mucolipidosis II is caused by mutations in GNPTA encoding the alpha/beta GIcNAc-1phosphotransferase. Nat. Med. 11, 1109-1112 (2005).

13 Bargal, R., Zeigler, M., Abu-Libdeh, B., Zuri, V., Mandel, H., Ben Neriah, Z. et al. When mucolipidosis III meets mucolipidosis II: GNPTA gene mutations in 24 patients. Mol. Genet. Metab. 88, 359-363 (2006).

14 Kojima, S., Okada, S., Kai, H., Ha, K., Nose, O., Ikeda, T. et al. A case of mucolipidosis II: biochemical, nutritional, and immunological studies. Brain. Dev. 1, 26-30 (1979).

15 Okada, S., Owada, M., Sakiyama, T., Yutaka, T. \& Ogawa, M. I-cell disease: clinical studies of 21 Japanese cases. Clin. Genet. 28, 207-215 (1985).

16 Grewal, S., Shapiro, E., Braunlin, E., Charnas, L., Krivit, W., Orchard, P. et al. Continued neurocognitive development and prevention of cardiopulmonary complications after successful BMT for I-cell disease: a long-term follow-up report. Bone Marrow Transplant. 32, 957-960 (2003).

17 Plante, M., Claveau, S., Lepage, P., Lavoie, E. M., Brunet, S., Roquis, D. et al. Mucolipidosis II: a single causal mutation in the $\mathrm{N}$-acetylglucosamine-1-phosphotransferase gene (GNPTAB) in a French Canadian founder population. Clin. Genet. 73, 236-244 (2008).

Supplementary Information accompanies the paper on Journal of Human Genetics website (http://www.nature.com/jhg) 